\title{
EFISIENSI USAHATANI PADI BERAS HITAM DI KABUPATEN KARANGANYAR
}

\author{
Arya Senna Putra, Nuning Setyowati, Susi Wuri Ani \\ Program Studi Agribisnis, Fakultas Pertanian, Universitas Sebelas Maret \\ E-mail: aryasp29@gmail.com
}

\begin{abstract}
The aim of this research were to analyze the revenue and the efficiency of black rice paddy farming in Karanganyar regency. The basic method of this research was descriptive analytic method. Location of the research was determined by purposive sampling in Karanganyar regency (census method). The number of black rice paddy farmers in Karanganyar regency was 23 people. Data used in the study were primary data as the main data and secondary data as supporting data. Data collected by observation, interview and record keeping. The results showed that black rice paddy farming in Karanganyar regency obtain the average revenue of IDR 8,974,565.22. Black rice paddy farming in Karanganyar regency were categorized efficient farming based on the average value of $R / C$ Ratio were 2.84 .
\end{abstract}

Keywords : black rice paddy, farms, revenue of farms, efficiency of farms.

\begin{abstract}
Abstrak: Penelitian ini bertujuan untuk menganalisis besarnya penerimaan dan efisiensi usahatani padi beras hitam di Kabupaten Karanganyar. Metode dasar pada penelitian ini adalah metode deskriptif analitik. Penentuan lokasi penelitian dilakukan secara sengaja yaitu di Kabupaten Karanganyar. Pengambilan responden dilakukan dengan cara sensus. Adapun jumlah petani padi beras hitam di Kabupaten Karanganyar berjumlah 23 orang. Data yang digunakan pada penelitian yaitu data primer sebagai data utama dan data sekunder sebagai data pendukung. Teknik pengumpulan data dilakukan dengan observasi, wawancara, dan pencatatan. Hasil penelitian menunjukkan bahwa usahatani padi beras hitam di Kabupaten Karanganyar memperoleh rata - rata penerimaan sebesar Rp 8.974.565,22. Usahatani padi beras hitam di Kabupaten Karanganyar dikategorikan usahatani yang efisien berdasarkan nilai $R / C$ Ratio rata - rata sebesar 2,84 .
\end{abstract}

Kata Kunci : padi beras hitam, usahatani, penerimaan usahatani, efisiensi usahatani.

\section{PENDAHULUAN}

Pembangunan sektor pertanian sebagai sektor pangan utama di Indonesia sangat penting dalam pembangunan Indonesia. Salah satu komoditas yang diusahakan oleh masyarakat Indonesia ialah padi yang kemudian diolah menjadi beras. Beras merupakan makanan pokok masyarakat Indonesia karena hampir seluruh masyarakat Indonesia mengkonsumsi beras. Secara umum ada 3 jenis beras yang ada di Indonesia yakni beras putih, beras merah, dan beras hitam.

Karanganyar merupakan salah satu daerah yang membudidayakan padi beras hitam. Lingkungan yang cocok untuk usahatani padi berupa suhu, kelembaban, ketersediaan air dan ketinggian tempat, membuat mayoritas penduduknya melakukan usahatani padi. Karakteristik padi beras hitam umumnya memiliki usia yang panjang yakni 100-120 hst, bentuk tanaman yang tinggi sekitar 130-140 $\mathrm{cm}$, jumlah bulir per malai 120-150, nasi agak bulat, pulen, kenyal dan wangi. Harga beras hitam yang beredar di pasaran cukup tinggi yakni Rp.15.000 hingga Rp 35.000 per Kg.

Beras hitam diminati masyarakat karena kandungannya. Beras hitam (Oryza Sativa $L$. indica) merupakan jenis beras yang mengandung 20,1 gram serat per 100 gram 
bahan makanan. Beras hitam juga mengandung antosianin yang berfungsi sebagai antioksidan di dalam tubuh sehingga dapat mencegah terjadinya penyakit penyumbatan pembuluh darah. Khasiat beras hitam yang beragam serta harga jual yang tinggi menjadi pertimbangan dalam budidaya beras hitam. Apabila input yang diberikan efisien maka hasil produksi dapat mencapai titik produksi tertinggi.

Berdasarkan uraian di atas maka permasalahan yang perlu dibahas berkaitan dengan padi beras hitam di Kabupaten Karanganyar antara lain: 1) Berapa besarnya penerimaan dari usahatani padi beras hitam di Kabupaten Karanganyar? 2) Bagaimanakah tingkat efisiensi usahatani padi beras hitam di Kabupaten Karanganyar?

\section{METODE PENELITIAN}

\section{Metode Dasar Penelitian}

Metode dasar yang digunakan dalam penelitian ini adalah metode deskriptif analitik. Metode ini mempunyai ciri-ciri, memusatkan diri pada pemecahan masalah yang aktual. Data yang dikumpulkan mula-mula disusun, dianalisis dan kemudian dijelaskan. Teknik pelaksanaan yang digunakan dalam penelitian adalah teknik survey. Teknik survei yaitu teknik pengumpulan data dari sejumlah unit atau individu dalam jangka waktu yang bersamaan (Surakhmad, 2004).

\section{Metode Penentuan Lokasi}

Penentuan daerah sampel dilakukan dengan sengaja. Penelitian dilakukan di dua kecamatan dari 17 kecamatan di Kabupaten Karanganyar. Dua kecamatan yang dipilih merupakan daerah sentra penghasil padi beras hitam di Kabupaten Karanganyar yakni Kecamatan Karangpandan dan Kecamatan Mojogedang. Setelah dilakukan penelitian dengan metode sensus maka ditemukan 23 petani yang menjalankan usahatani padi beras hitam.

\section{Metode Pengambilan Sampel}

Metode pengambilan sampel yang digunakan adalah dengan metode sensus. Menurut Susanto (2006), jika dalam suatu penelitian jumlah populasinya relatif kecil (< 30 orang) maka seluruh populasi dijadikan sebagai sumber data.
Pengambilan responden dilakukan dengan cara sensus yaitu dengan cara mencatat elemen yang diselidiki yakni menyelidiki semua gejala, semua kejadian atau peristiwa. Hasil dari sensus adalah karakteristik yang sesungguhnya. Kumpulan dari seluruh elemen (responden) dinamakan populasi atau universe (Marzuki, 2002).

\section{Metode Analisis Data}

Penerimaan usahatani. Besarnya penerimaan usahatani padi beras hitam oleh petani dapat diketahui dengan menggunakan rumus $\mathrm{TR}=$ Y.Py dimana TR $=$ Penerimaan total usahatani padi beras hitam $(\mathrm{Rp} / \mathrm{Ha} / \mathrm{MT}), \mathrm{Y}=$ Kuantitas produksi usahatani padi beras hitam $(\mathrm{Kw} / \mathrm{Ha} / \mathrm{MT})$, Py $=$ Harga produksi usahatani padi beras hitam $(\mathrm{Rp} / \mathrm{Kw})$. Analisis Efesiensi Usahatani. Analisis efisiensi usahatani merupakan analisis yang dilakukan untuk mengetahui apakah kegiatan yang selama ini dilakukan termasuk kategori efisien atau tidak. Analisis efisiensi dilakukan dengan membagi total penerimaan dengan total biaya dengan menggunakan rumus $\mathrm{R} / \mathrm{C}=\mathrm{TR} / \mathrm{TC}$ dimana $\mathrm{R} / \mathrm{C}$ merupakan revenue cost ratio, TR merupakan total penerimaan $(\mathrm{Rp})$, dan $\mathrm{TC}$ adalah total biaya (Rp). Kriteria dalam analisis $\mathrm{R} / \mathrm{C}$ ratio adalah $\mathrm{R} / \mathrm{C}>1$ berarti usahatani efisien, $\mathrm{R} / \mathrm{C}=$ 1yang berarti usahatani impas, dan $\mathrm{R} / \mathrm{C}<1$ yang berarti usahatani tidak efisien (Soekartawi, 2006).

\section{HASIL DAN PEMBAHASAN}

\section{Karakteristik Petani}

Karakteristik Petani. Jumlah petani sampel yang diambil adalah 23 petani dengan rata-rata umur petani adalah 51 tahun. Umur tersebut termasuk ke dalam golongan usia produktif karena berada di antara 15 hingga 64 tahun sehingga petani memiliki kemauan dan kemampuan yang tinggi dalam kegiatan usahatani padi beras hitam. Pengalaman petani dalam usahatani padi beras hitam di Kabupaten Karanganyar rata-rata selama 3 tahun. Rata-rata petani memiliki 4 anggota keluarga dan hanya 1 anggota keluarga yang aktif dalam kegiatan usahatani. Sedangkan rata-rata luas lahan garapan dalam kegiatan usahatani padi beras 
Tabel 1. Rata-rata Penggunaan Sarana Produksi pada Usahatani Padi Beras Hitam Musim Tanam April Juli 2016 di Kabupaten Karanganyar

\begin{tabular}{llrr}
\hline No & \multicolumn{1}{c}{ Sarana Produksi } & $\begin{array}{c}\text { Per Usahatani } \\
(\mathbf{0 , 1 7} \text { ha) }\end{array}$ & \multicolumn{2}{c}{$\begin{array}{c}\text { Per Hektar } \\
(\mathbf{1} \text { ha })\end{array}$} \\
\hline 1 & Benih & $7,09 \mathrm{Kg}$ & $41,69 \mathrm{Kg}$ \\
2 & Pupuk Organik & $2.021,74 \mathrm{Kg}$ & $11.892,58 \mathrm{Kg}$ \\
3 & Pestisida Organik & $0,78 \mathrm{~L}$ & $4,60 \mathrm{~L}$ \\
\hline
\end{tabular}

Sumber: Analisis Data Primer, 2016

Tabel 2. Rata-rata Penggunaan Tenaga Kerja pada Usahatani Padi Beras Hitam Musim Tanam April Juli 2016 di Kabupaten Karanganyar

\begin{tabular}{llrrrrrr}
\hline \multirow{2}{*}{ Ko } & \multicolumn{2}{c}{ TKD $($ HKP) } & \multicolumn{2}{c}{ TKL (HKP) } & \multicolumn{2}{c}{ Jumlah (HKP) } \\
\cline { 2 - 7 } & & Per UT & Per Ha & Per UT & Per Ha & Per UT & Per Ha \\
\hline 1 & Persemaian Bibit & 1,78 & 10,49 & 0,91 & 5,37 & 2,69 & 15,86 \\
2 & Pengolahan Lahan & 1,65 & 9,72 & 3,65 & 21,48 & 5,30 & 31,20 \\
3 & Penanaman & 1,00 & 5,88 & 5,65 & 33,25 & 6,65 & 39,13 \\
4 & Pemupukan & 0,96 & 5,63 & 2,52 & 14,83 & 3,48 & 20,46 \\
5 & Penyiangan & 0,96 & 5,63 & 4,91 & 28,90 & 5,87 & 34,53 \\
6 & Pengendalian Hama Penyakit & 0,52 & 3,07 & 2,09 & 12,28 & 2,61 & 15,35 \\
7 & Pemanenan & 0,96 & 5,63 & 6,48 & 38,11 & 7,43 & 43,73 \\
8 & Penjemuran & 1,04 & 6,14 & 1,91 & 11,25 & 2,96 & 17,39 \\
\hline & Jumlah & 8,87 & 52,19 & 28,12 & 165,47 & 36,99 & 217,65 \\
\hline
\end{tabular}

Sumber: Analisis Data Primer, 2016

hitam di Kabupaten Karanganyar adalah seluas $1.652,17 \mathrm{~m}^{2}$ atau 0,17 ha.

Penggunaan Sarana Produksi. Sarana produksi merupakan sarana yang dibutuhkan dalam usahatani padi beras hitam agar kegiatan usahatani dapat berjalan dengan baik dan dapat menghasilkan produksi sesuai dengan harapan. Sarana produksi yang dibutuhkan dalam usahatani padi beras hitam adalah benih, pupuk organik, dan pestisida organik. Pembahasan penggunaan sarana produksi padi beras hitam dapat dilihat pada Tabel 1. Tabel 1, menunjukkan benih yang dibutuhkan untuk rata-rata per usahatani adalah sebesar $7,09 \mathrm{Kg}$ dan 41,69 Kg per hektar. Pupuk organik yang dibutuhkan per usahatani padi beras hitam ratarata sebesar 2.021,74 $\mathrm{Kg}$ dan $11.892,58 \mathrm{Kg}$ per hektar. Sedangkan rata-rata pestisida yang dibutuhkan per usahatani sebesar $0,78 \mathrm{~L}$ dan 4,6 L per hektar.

Penggunaan Tenaga Kerja. Tenaga kerja merupakan jenis input atau masukan lain yang memiliki peranan penting dalam keberlangsungan usahatani padi beras hitam.
Tenaga kerja secara dapat berasal dari dalam keluarga maupun dari luar keluarga. Tenaga kerja berperan dalam semua tahapan usahatani padi beras hitam, seperti menanam, penyiangan, pemupukan, penyemprotan hama, panen serta pengangkutan hasil panen. Ratarata penggunaan tenaga kerja pada usahatani padi beras hitam dapat dilihat pada Tabel 2 . Tabel 2, menunjukan rata-rata keseluruhan penggunaan tenaga kerja untuk satu kali musim tanam adalah sebesar 36,99 HKP per usahatani (0,17 ha) atau sebesar 217,65 HKP per hektar. Penggunaan tenaga terdiri dari 8,87 HKP tenaga kerja dalam dan 28,12 HKP tenaga kerja luar per usahatani $(0,17 \mathrm{ha})$, atau sebesar 52,19 HKP tenaga kerja dalam dan 165,47 HKP tenaga kerja luar untuk 1 hektar. Penggunaan Peralatan. Peralatan merupakan salah satu unsur penting dalam usahatani padi beras hitam. Peralatan dapat menunjang kegiatan usahatani padi beras hitam. Peralatan yang digunakan oleh petani dalam usahatani padi beras hitam diantaranya adalah cangkul, sabit, garu, linggis, dan sprayer. 
Tabel 3. Rata-rata Penggunaan Peralatan pada Usahatani Padi Beras Hitam Musim Tanam April - Juli 2016 di Kabupaten Karanganyar

\begin{tabular}{|c|c|c|}
\hline No & Jenis Peralatan & Per Usahatani (Unit/0,17 ha) \\
\hline 1 & Cangkul & 2 \\
\hline 2 & Sabit & 2 \\
\hline 3 & Garu & 1 \\
\hline 4 & Linggis & 0 \\
\hline 5 & Tleser & 0 \\
\hline 6 & Sprayer & 0 \\
\hline 7 & Traktor & 0 \\
\hline
\end{tabular}

Sumber: Analisis Data Primer, 2016

Tabel 4. Rata-rata Penerimaan Usahatani Padi Beras Hitam Musim Tanam April - Juli 2016 di Kabupaten Karanganyar

\begin{tabular}{|c|c|c|c|}
\hline No & Uraian & $\begin{array}{c}\text { Per Usahatani } \\
(0,17 \text { ha })\end{array}$ & $\begin{array}{c}\text { Per Hektar } \\
\text { (1 ha) }\end{array}$ \\
\hline 1 & Produksi & $740,87 \mathrm{Kg}$ & $4.358,06 \mathrm{Kg}$ \\
\hline 2 & Harga Beras PK & $12.108,70$ & $12.108,70$ \\
\hline 3 & Penerimaan & Rp 8.974.565,22 & Rp 52.791.560,10 \\
\hline
\end{tabular}

Sumber: Analisis Data Primer, 2016

Tabel 5. Hasil Analisis Efisiensi Usahatani Padi Beras Hitam Musim Tanam April - Juli 2016 di Kabupaten Karanganyar

\begin{tabular}{ccc}
\hline No & Nilai R/C & Jumlah (Orang) \\
\hline 1 & $<1$ & 0 \\
2 & $=1$ & 0 \\
3 & $>1$ & 23 \\
\hline Rata-rata & 2,84 & \\
\hline Jumlah & & 23 \\
\hline
\end{tabular}

Sumber: Analisis Data Primer, 2016

Rata-rata penggunaan peralatan dalam usahatani padi beras hitam dapat dilihat pada Tabel 3. Tabel 3, menunjukkan bahwa tidak semua petani memiliki peralatan seperti linggis, tleser, sprayer, dan traktor. Peralatan produksi yang dimiliki oleh petani yakni cangkul, sabit dan garu. Jenis peralatan yang banyak dimiliki petani yakni cangkul dengan rata-rata sebanyak 2 unit per usahatani dan sabit rata-rata sebanyak 2 unit per usahatani.

\section{Analisis Penerimaan dan Efisiensi Usahatani}

Penerimaan. Penerimaan merupakan jumlah kotor uang yang diterima petani dari kegiatan usahatani padi beras hitam. Penerimaan merupakan jumlah perkalian produksi beras pecah kulit (PK) dengan harga beras pecah kulit. rata-rata penerimaan yang dapat diterima petani dari usahatani padi beras hitam sebesar
Rp 8.974.565,22 per usahatani. Nilai tersebut diperoleh dari hasil perkalian jumlah produksi beras pecah kulit sebesar 740,87 Kg dengan harga beras pecah kulit Rp 12.108.70 per Kg. Sedangkan per 1 Hektar diperoleh penerimaan sebesar Rp 52.791.560,10 dari hasil produksi sebesar 4.358,06 Kg dikali harga rata-rata beras pecah kulit $\mathrm{Rp} 12.108 .70$ per $\mathrm{Kg}$. Penerimaan petani dari usahatani padi beras hitam dapat dilihat pada Tabel 4.

Analisis Efisiensi Usahatani. Analisis efisiensi usahatani adalah analisis yang dilakukan untuk mengetahui apakah usahatani yang dilakukan oleh petani sudah efisien, impas, atau tidak efisien. Analisis efisiensi dilakukan dengan membandingkan penerimaan yang diterima oleh petani dengan biaya usahatani yang dikeluarkan. Tabel 5 menunjukkan bahwa seluruh petani telah melakukan usahatani padi 
beras hitam secara efisien. Hal ini ditunjukkan dengan semua petani padi beras hitam yang berjumlah 23 orang memiliki nilai $\mathrm{R} / \mathrm{C}$ diatas 1 yang berarti sudah efisien. Rata-rata nilai $\mathrm{R} / \mathrm{C}$ yang diterima oleh seluruh petani responden adalah sebesar 2,84. Hal tersebut menunjukkan dalam setiap investasi yang dilakukan petani sebesar Rp 1, petani akan memperoleh penerimaan sebesar Rp. 2,84 sehingga usahatani padi beras hitam layak di usahakan. Hasil analisis efisiensi usahatani padi beras hitam di Kabupaten Karanganyar dapat dilihat pada Tabel 5.

\section{KESIMPULAN}

Berdasarkan hasil penelitian dan pembahasan yang telah diuraikan pada bab sebelumnya maka dapat diambil beberapa kesimpulan sebagai berikut: 1) Besarnya penerimaan usahatani padi beras hitam yakni sebesar Rp 8.974.565,22 per usahatani $(0,17$ ha) atau Rp 52.791.560,10 per hektar. 2) Usahatani padi beras hitam di Kabupaten Karanganyar sudah efisien dengan nilai $\mathrm{R} / \mathrm{C}$ rata-rata sebesar 2,84.

Saran yang dapat diberikan adalah sebagai berikut : 1) Petani dalam kegiatan usahatani padi beras hitam sebaiknya mengurangi masukan pupuk organik karena jumlah penggunaan pupuk rata - rata sebesar 11,892 ton per hektar, sedangkan jumlah pupuk yang dianjurkan menurut metode SRI yakni sebesar 10 ton per hektar. 2) Petani dalam kegiatan usahatani padi beras hitam sebaiknya menyesuaikan masukan sesuai dengan anjuran metode SRI yakni penggunaan 1 benih per lubang sedangkan usahatani padi beras hitam di Karanganyar sebanyak 2 benih per lubang.

\section{DAFTAR PUSTAKA}

Badan Pusat Statistik. 2015. Jawa Tengah Dalam Angka 2015. Badan Pusat Statistik Provinsi Jawa Tengah.

Direktorat Jenderal Pengolahan dan Pemasaran Hasil Pertanian. 2015. Produksi Padi Beras Hitam tahun 2015. Departemen pertanian. Jakarta.

Kusmiadi, R. 2008. Varietas Beras Dengan Komposisi Kimiawi Zat Penyusunnya. FPPB UBB. Bangka Belitung.

Marzuki 2002. Metodologi Riset. BPFE UII. Yogyakarta.

Persatuan Ahli Gizi Indonesia. 2009. Tabel Komposisi Pangan Indonesia. PT Elex Media Komputindo. Jakarta.

Soekartawi. 2006. Analisis Usahatani. Universitas Indonesia Press. Jakarta.

Surakhmad, W. (2004). Pengantar Penelitian Ilmiah Dasar Metode Teknik. Tarsito. Bandung.

Susanto. 2006. Metode Penelitian Sosial. UNS Press. Surakarta. 